\title{
Muscle fatigue secondary to hyperlactatemia and B2 agonists use in severe
}

\section{asthma crisis: Literature review and case report}

Aponte Jorge 1, Forero Yency², Diaz Martha3 ${ }^{3}$ Estupiñán Maria ${ }^{3}$, Martin Daniel ${ }^{3}$, Zapata Martin4,

Ospina Maria ${ }^{1}{ }^{1}$, Sanchez Alexander ${ }^{1}$, Cano Natalia ${ }^{3}$ Chaparro Yesid ${ }^{4}$

1. Department of Critical Care, Hospital de la Samaritana, Bogota Colombia

2. Internal Medicine, Universidad de la Sabana, Bogota Colombia

3. Medicine, Universidad de la Sabana, Bogota Colombia

4. Internal Medicine Universidad del el Bosque, Bogota Colombia

\section{CASE STUDY}

Please cite this paper as: Aponte J, Forero $\mathrm{Y}$, Diaz $\mathrm{M}$, Estupiñan M, Martin D, Zapata M, Ospina MT, Sanchez A, Cano N, Chaparro Y. Muscle fatigue secondary to hyperlactatemia and B2 agonists use in severe asthma crisis: Literature review and case report. AMJ 2018;11(12):549555. https://doi.org/10.21767/AMJ.2018.3512

\section{Corresponding Author:}

Jorge Enrique Aponte

Department of Critical Care, Internal Medicine Hospital de la Samaritana, Hospital de Santa Clara, Bogota Colombia Email: jorapon3777@hotmail.com

\section{ABSTRACT}

The definition and approach of hyperlactatemia classically has been related to tissue hypoperfusion, hepatic insufficiency, and anaerobic metabolism. Nonetheless, there are few aetiologies known which could produce it. Muscle fatigue in patients with chronic obstructive pulmonary disease (COPD) or asthma, as well as the use of inhaled B2 agonist, is associated with hepatic noradrenaline release, activation of glycolysis (converting glucose to pyruvate or lactate), and consequently, an increase in lactate.

\section{Key Words}

Hyperlactatemia, adrenergic beta 2 agonist, status asthmaticus, muscle fatigue

\section{Implications for Practice:}

\section{What is known about this subject?}

The case of patient, admitted to intensive care due to hyperlactatemia secondary to B2 agonist in a severe asthma crisis, is presented hereof.

\section{What new information is offered in this case study?}

The definition and approach of hyperlactatemia classically has been related to tissue hypoperfusion, hepatic insufficiency, and anaerobic metabolism. Nevertheless, there are few aetiologies known which could produce it.

3. What are the implications for research, policy, or practice?

Differential diagnosis of hyperlactatemia in ICUs has a wide range of possibilities.

\section{Background}

Severe asthma is characterized by respiratory acidosis secondary to progressive hypercapnia and severe obstruction to airflow. Yet, during an asthma attack, a large number of acid base alterations might be presented, including metabolic acidosis with elevated anion gap secondary to hyperlactatemia. Such alteration has been related mainly to tissue hypoperfusion, however, there are other alterations, such as the use of B2 agonists and muscle fatigue in patients with asthma, which generates alteration in the acid-base homeostasis.

Prompt recognition of lactic acidosis, by the use of $B 2$ agonists, and muscle fatigue is a decisive factor in the prognosis and treatment of patients with chronic pulmonary obstructive diseases. Metabolic acidosis, on one side, represents a respiratory insufficiency, and on the other side, reflects the treatment with B2 agonist, which produces dynamic hyperinflation, an increase in the positive pressure at the end of expiration, and a respiratory failure. For this 
reason, it is considered vital the knowledge of the differential diagnosis and pathophysiology of hyperlactatemia in the intensive care unit, emphasizing in the muscle fatigue and the use of B2 agonists in patients with asthma. So, in this report, it is presented first, a patient with severe asthma and hyperlactatemia secondary to the last two causes aforementioned, and second, a literature review of this association.

Hyperlactatemia, conventionally, has been associated to tissue hypoperfusion, hepatic insufficiency, and anaerobic metabolism. Nonetheless, other aetiologies, not related to tissue hypoperfusion, have been described, which, include the use of B2 agonists and muscle fatigue in patients with chronic pulmonary diseases such as COPD and asthma. Well then, in such pulmonary conditions, it is described an increase in the respiratory work which produces muscular fatigue, alongside a subsequent increase in metabolic demands (predominantly anaerobic) and generation of hyperlactatemia. Differential diagnosis in patients with hyperlactatemia in critical care units is fundamental; thus, in this paper, it is presented the case of a patient with a severe asthma crisis, ventilatory failure, and hyperlactatemia secondary to B2 agonist administration and muscle fatigue.

\section{Case details}

The patient described hereof is a 23-years-old Hispanic women, with a relevant previous medical record for persistent asthma, and multiples visits to the emergency department for severe asthma crisis, dry cough, and dyspnoea for the last 12 hours, without any response to either inhaled B2 agonist or steroids. The patient progressed to a ventilatory insufficiency and, after her admission to the ER, airway intubation and mechanical ventilation was rapidly required. In the intensive care unit (ICU), metabolic acidosis, hyperlactatemia, hyperglycaemia, and an increase in white blood cells, which required insulin and potassium drip (Table 1), were reported. The clinical picture is interpreted as an acute severe exacerbation of the patient's asthma, which led to ventilatory insufficiency type I, hyperglycaemia secondary to a stress state, and hyperlactatemia type B (secondary to the use of B2 agonist). Hence, after an appropriate treatment and resolution of the patient's bronchoconstriction, mechanical ventilation was retired, and subsequently, blood chemistry demonstrated resolution of the hyperlactatemia, hyperglycaemia, and electrolyte imbalance.

\section{Discussion}

Lactic acid is the final product of anaerobic glycolysis in tissues. ${ }^{1} \quad$ Biochemically; it corresponds to a hydroxycarboxylic acid that has two isomeric forms: Llactate and D-lactate. L-lactate is the only one formed by human metabolism and it is currently measured to indirectly evaluate hypoperfusion states. ${ }^{2} \mathrm{D}$-lactate is found as a product of bacterial metabolism and bacterial fermentation of undigested carbohydrates in the gastrointestinal tract. Physiological sources of lactate are found in foods such as wine or preserved food in vinegar or brine. ${ }^{3,4}$

From pyruvate, L-lactate is produced by a reversible reaction of oxidoreduction catalysed by the enzyme Llactate dehydrogenase (LD) located mainly in the cytosol. A cofactor of nicotinamide adenine dinucleotide (NADH) has to be oxidize to nicotinamide adenine dinucleotide (NAD $+)^{2,5}$ Under aerobic conditions pyruvate is produced by a glycolytic pathway to subsequently enter the Krebs cycle; however, under anaerobic conditions lactate enters the Cori cycle as a substrate for gluconeogenesis from tissues in the liver and kidneys. ${ }^{6}$

The causes of hyperlactatemia are variable and depend on the clinical status of the patient (Table 2). So, in general terms, hyperlactatemia could be secondary to an increased production, a decreased clearance, or a combination of both. ${ }^{7}$ Cohen and Woods divided the physiopathological mechanisms by which hyperlactatemia occurs in two large groups: type A hyperlactatemia, which corresponds to hypoxia and tissue hypoperfusion states, and hyperlactatemia B, which in turn, is subdivided into B1, B2, and $\mathrm{B} 3$, and corresponds to causes not related to tissue hypoxia $^{8}$ (Figure 1 ).

Lactic acidosis is associated to an increase in serum lactate, it usually occurs in critically ill patients and it is correlated to hypoxia or tissue hypoperfusion secondary to sepsis or cardiovascular collapse. ${ }^{9} \quad$ Nevertheless, differential diagnoses of this condition should be made due to the fact that medications and other states can contribute to hyperlactatemia. In our patients, we understood the use of inhaled / intravenous beta agonists, such as salbutamol and albuterol, specifically used in patients with asthma crisis.

Furthermore, lactic acidosis has been registered in patients with severe asthma, and it has been suggested that it is secondary to an inadequate oxygen supply in respiratory muscle when respiratory work is increased. Yet, there is not enough evidence since there are reports which have shown 
that muscle activity does not directly correlates with increases in lactate.

To explain the association between hyperlactatemia and B2 agonist use, there were found theories which propose that an exogenous or endogenous adrenergic stimulation might be associated with the formation of lactate in the body. The mechanism behind it, is an increase in the metabolic effects of fatty acids, glucose concentrations, glycogenolysis, and gluconeogenesis by stimulation of beta-adrenergic receptors, leading to glycolysis, and increased pyruvate levels; in a state of hypoxia, such as an asthma crisis, it could increase free fatty acids which avoid Krebs cycle and induce anaerobic metabolism with subsequent increased lactate levels. ${ }^{10}$

Previously, it was suggested that lactic acidosis in asthma crisis is secondary to a state of hidden shock or to the production of lactate by the respiratory muscles or pulmonary parenchyma. Despite this, when analysing the cases, it was evident that there were no signs of shock in the patient, neither an overuse in the respiratory muscles since, the administration of muscle relaxant, was administered and clinical or serum evidence of hepaticrenal organic dysfunction was not found. ${ }^{11}$ Thanks to the aforementioned assumption, it was thought of the possibility that the development of this condition was secondary to other causes, such an adverse drug effect, mainly produced by inhaled beta agonists.

Stimulation of beta 2 adrenergic receptors leads to the mobilization of energy reserves, and the adrenergic state, increases glycogenolysis, lipolysis, and gluconeogenesis. Therefore, the administration of beta 2 agonist results in an increase of the concentrations of pyruvate, which, turns to lactate and enters the respiratory anaerobic chain. ${ }^{12-14}$

Early stages of asthma attacks lead to respiratory alkalosis secondary to hyperventilation. When hyperventilation persists over time; $\mathrm{CO}_{2}$ is retained leading to respiratory acidosis. Series of case reports, shown that continuous or frequent nebulizations with albuterol led to paradoxical metabolic acidosis without the presence of sepsis, hypovolemia or hypoxia. When albuterol administration was spaced, progressive decrease in serum levels were seen without the need to adjust or add other Treatments. ${ }^{10}$

In a prospective study, nine healthy volunteers received a dose of IV salbutamol, demonstrating an increase in ventilatory demand by raising metabolic rate and serum lactate, which suggests that this treatment can clinically worsen patients with asthma crisis and reduced ventilatory capacity. ${ }^{15}$

Among other reported cases, Rodrigo et al., carried out a prospective and descriptive study to analyse lactate levels and the effects of bronchodilators in adults with severe asthma, treated with high doses of albuterol. The results evidenced that up to 50 per cent of the patients analysed had significantly elevated plasma lactate levels, and that the increase of hyperlactatemia occurred during the first hours of treatment with inhaled beta agonist. It should be kept in mind that a previous hyperadrenergic state (respiratory distress during the crisis, anxiety) might also predispose to the development of such condition. $^{16}$

Well then, Manara et al., present the case of a patient, with an intentional overdose of beta agonist, who developed lactic acidosis in the absence of respiratory distress or metabolic disease. ${ }^{14}$ Furthermore, the study presented by Prakash et al., proposed that hyperlactatemia is the result of a hyperadrenergic state during asthma crisis, where both endogenous and exogenous factors could influence the administration of beta agonists in large quantities. ${ }^{17}$ Similar cases have been reported, not only in adults, but also in children aged from 7 to 16 years old with severe asthma crisis and the presence of hyperlactatemia after the administration of beta agonist, either inhaled or intravenously. ${ }^{13,18-20}$

It is important to recognize the relationship between hyperlactatemia and the continuous administration of beta agonist, often used in critically ill patients with bronchospasm, due to the fact that an elevated lactate could lead to misinterpretation of clinical improvement, changes in pharmacotherapeutics, or initiation of treatment schemes that do not correspond to the pathology itself. ${ }^{10}$

Clinical importance is based on the paradoxical response in patients with bronchospasm; even though, after administration of beta 2 agonist resolves bronchospasm in the presence of metabolic acidosis, it leads to a compensation with tachypnea and persistent dyspnoea; symptoms and signs which, on one side, could be confusing, even for an experienced clinician, and on the other side, might create a vicious cycle that can result in ventilatory failure. $^{21,22}$ Additionally, hyperlactatemia could complicate the patient's condition and significantly influence treatment protocols. Well then, the fact that our patient, notwithstanding the hemodynamic and cardiovascular stability, and the low use of inhaled beta agonist doses, 
progressed to an important elevation in lactate, made us believe that more studies are required to determine the exact aetiology and the reason why only a small proportion of patients develop this condition. In addition, series of cases are needed to recognize patterns and characteristics that determine the predisposition and probability of developing such condition. ${ }^{22,23}$

In the series of studies published between patients with normal vs. high lactate concentration with no association were found in terms of outcomes, prognosis and relapse rate. $^{24}$ Hitherto, there is no evidence of a based management for this type of clinical situations; so, according to the case reports found, the strategies proposed include, reducing dose of inhaled B2 agonist or switching to anticholinergics. Thus, future studies are still needed to establish the aetiology, epidemiology, and management of this paradoxical condition.

\section{Conclusion}

To conclude, differential diagnosis of hyperlactatemia in ICUs has a wide range of possibilities. The most common cause is related to states of tissue hypoperfusion, septic shock, or hepatic dysfunction; yet, it is necessary to take into consideration that there are other aetiologies of hyperlactatemia, such as inhaled B2 agonists use, and muscle fatigue secondary to ventilatory insufficiency, most of the time dismissed during treatment or evaluation. More studies should be performed to evaluate pharmacological strategies for bronchodilation, especially in patients with ventilatory failure. Therefore, it is proposed, like other authors does, a reduction of inhaled B2 agonist doses or shift to anticholinergics.

\section{References}

1. Stacpoole PW, Wright EC, Baumgartner TG, et al. Natural history and course of acquired lactic acidosis in adults. DCA-Lactic Acidosis Study Group. Am J Med. 1994;97(1):47-54. Available from:

http://www.ncbi.nlm.nih.gov/pubmed/8030656

2. Adeva-Andany $M$, López-Ojén $M$, Funcasta-Calderón $\mathrm{R}$, et al. Comprehensive review on lactate metabolism in human health. Mitochondrion. 2014;17:76-100. Available from: http://www.ncbi.nlm.nih.gov/pubmed/24929216

3. Uribarri J, Oh MS, Carroll HJ. D-lactic acidosis. A review of clinical presentation, biochemical features, and pathophysiologic mechanisms. Medicine (Baltimore). 1998;77(2):73-82. Available from: http://www.ncbi.nlm.nih.gov/pubmed/9556700
4. Zhang DL, Jiang ZW, Jiang J, et al. D-lactic acidosis secondary to short bowel syndrome. Postgrad Med J. 2003;79(928):110-2. Available from: http://www.ncbi.nlm.nih.gov/pubmed/12612331

5. Le A, Cooper CR, Gouw AM, et al. Inhibition of lactate dehydrogenase $A$ induces oxidative stress and inhibits tumor progression. Proc Natl Acad Sci. 2010;107(5):2037-42. Available from: http://www.ncbi.nlm.nih.gov/pubmed/20133848

6. Andersen LW, Mackenhauer J, Roberts JC, et al. Etiology and therapeutic approach to elevated lactate levels. Mayo Clin Proc. 2013;88(10):1127-40. Available from: http://www.ncbi.nlm.nih.gov/pubmed/24079682

7. Luft D, Deichsel G, Schmülling RM, et al. Definition of clinically relevant lactic acidosis in patients with internal diseases. Am J Clin Pathol. 1983;80(4):484-9. Available from: http://www.ncbi.nlm.nih.gov/pubmed/6624712

8. Cohen RD, Woods HF. Clinical and biochemical aspects of lactic acidosis. Blackwell Scientific Publications; 1976. $276 \mathrm{p}$.

9. Veenith TV, Pearce A. A case of lactic acidosis complicating assessment and management of asthma. Int Arch Med. 2008;1(1):3. Available from: http://www.ncbi.nlm.nih.gov/pubmed/18471314

10. Patel S, Hanhan U, Perkowski C, et al. Continuous albuterol treatments may lead to lactic acidosis in children with status asthmaticus. Int J Aller Medicat. 2017;3(310):232572-3308. Available from: https://www.clinmedjournals.org/articles/ijam/internati onal-journal-of-allergy-medications-ijam-3-023.pdf

11. Manthous CA. Lactic acidosis in status asthmaticus: three cases and review of the literature. Chest [Internet]. 2001;119(5):1599-602. Available from: http://www.ncbi.nlm.nih.gov/pubmed/11348975

12. Blohm E, Lai J, Neavyn M. Drug-induced hyperlactatemia. Clin Toxicol. 2017;55(8):86978. Available from:

https://www.tandfonline.com/doi/full/10.1080/155636 50.2017.1317348

13. Saadia TA, George M, Lee H. Lactic acidosis and diastolic hypotension after intermittent albuterol nebulization in a pediatric patient. Respir Med case reports. 2015;16:89-91. Available from: http://www.ncbi.nlm.nih.gov/pubmed/26744665

14. Manara A, Hantson $P$, Vanpee $D$, et al. Lactic acidosis following intentional overdose by inhalation of salmeterol and fluticasone. CJEM. 2012;14(6):378-81. Available from: http://www.ncbi.nlm.nih.gov/pubmed/23131487

15. Tobin AE, Pellizzer AM, Santamaria JD. Mechanisms by which systemic salbutamol increases 
ventilation. Respirology. 2006;11(2):182-7. Available from: http://www.ncbi.nlm.nih.gov/pubmed/16548904

16. Rodrigo GJ, Rodrigo C. Elevated plasma lactate level associated with high dose inhaled albuterol therapy in acute severe asthma. Emerg Med J. 2005;22(6):404-8. Available

from: http://www.ncbi.nlm.nih.gov/pubmed/15911945

17. Prakash S, Mehta S. Lactic acidosis in asthma: report of two cases and review of the literature. Can Respir J. 2002;9(3):203-8. Available from: http://www.ncbi.nlm.nih.gov/pubmed/12068341

18. Saxena R, Marais G. Salbutamol: beware of the paradox! Case Reports. 2010;2010:bcr0120102665bcr0120102665. Available from: http://www.ncbi.nlm.nih.gov/pubmed/22778368

19. Tomar RPS, Vasudevan R. Metabolic acidosis due to inhaled salbutamol toxicity: A hazardous side effect complicating management of suspected cases of acute severe asthma. Med journal, Armed Forces India. 2012;68(3):242-4. Available from: http://www.ncbi.nlm.nih.gov/pubmed/24532877

20. Meert KL, Clark J, Sarnaik AP. Metabolic acidosis as an underlying mechanism of respiratory distress in children with severe acute asthma*. Pediatr Crit Care Med. 2007;8(6):519-23. Available from: http://www.ncbi.nlm.nih.gov/pubmed/17906597

21. Dodda VR, Spiro P. Can albuterol be blamed for lactic acidosis? Respir Care. 2012;57(12):2115-8. Available from:

http://www.ingentaconnect.com/content/jrcc/rc/preprints/rc01810r3dodda

22. McGonigle R, Woods RA. Take my breath away: a case of lactic acidosis in an asthma exacerbation. CJEM. 2011;13(4):284-8. Available from: http://www.ncbi.nlm.nih.gov/pubmed/21722560

23. Creagh-Brown BC, Ball J. An under-recognized complication of treatment of acute severe asthma. Am J Emerg Med. 2008;26(4):514.e1-514.e3. Available from: http://www.ncbi.nlm.nih.gov/pubmed/18410827

24. Lewis LM, Ferguson I, House SL, et al. Albuterol administration is commonly associated with increases in serum lactate in patients with asthma treated for acute exacerbation of asthma. Chest. 2014;145(1):53-9. Available from: http://linkinghub.elsevier.com/retrieve/pii/S001236921 5493286

\section{PEER REVIEW}

Not commissioned. Externally peer reviewed.

\section{CONFLICTS OF INTEREST}

The authors declare that they have no competing interests.

\section{FUNDING}

None

\section{PATIENT CONSENT}

The authors, Aponte J, Forero $Y$, Diaz $M$, Estupiñan $M$, Martin D, Zapata M, Ospina MT, Sanchez A, Cano N, Chaparro $Y$, declare that:

1. They have obtained written, informed consent for the publication of the details relating to the patient(s) in this report.

2. All possible steps have been taken to safeguard the identity of the patient(s).

3. This submission is compliant with the requirements of local research ethics committees. 
Figure 1: Physiopathology of hyperlactatemia

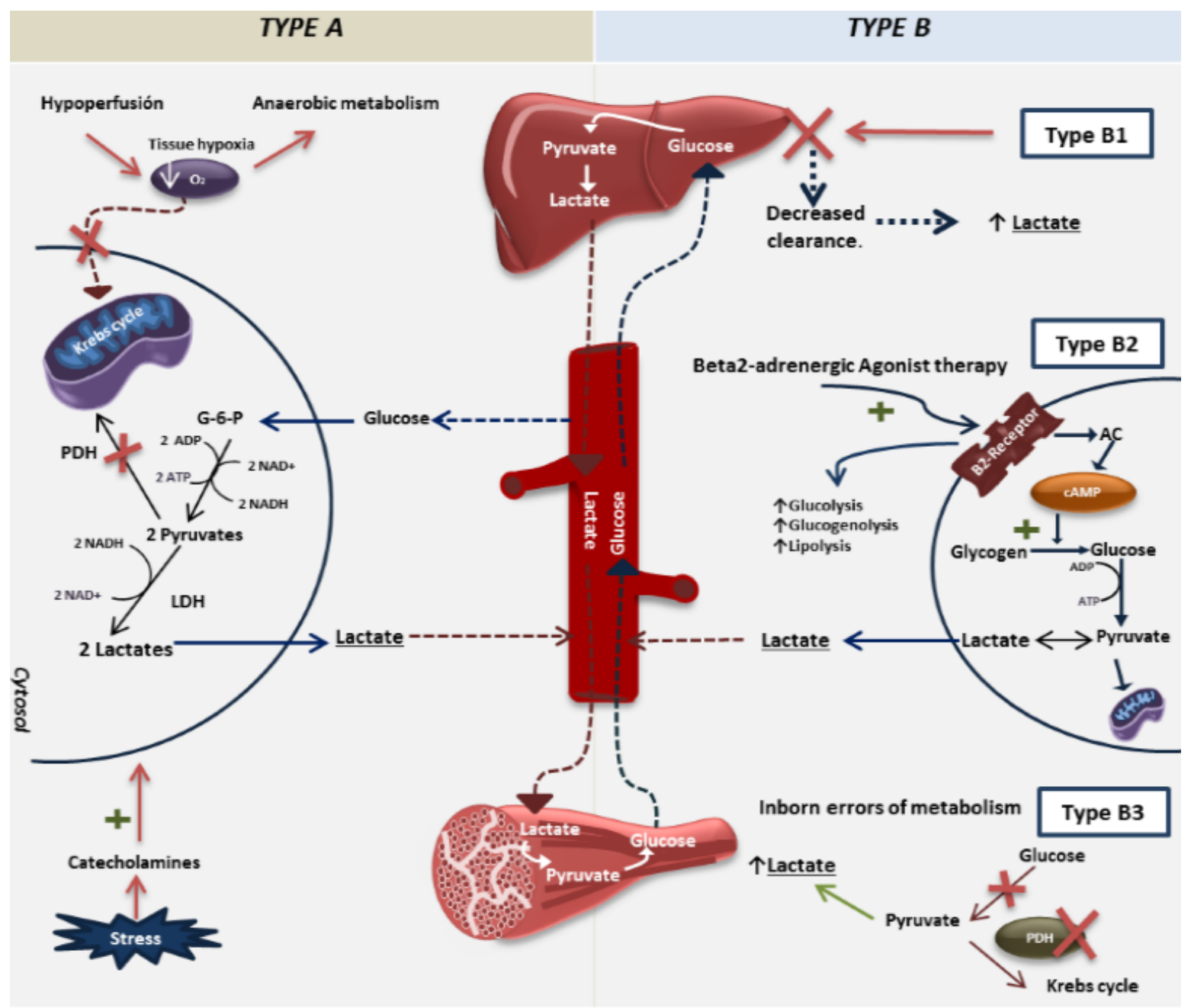

Fig. 1 Physiopathology of hyperlactatemia. LDH: Lactate Dehydrogenase. PDH: Pyruvate Dehydrogenase. AC: Cyclase adenylate

Table 1: Laboratory test

\begin{tabular}{|c|c|c|c|}
\hline \multicolumn{2}{|l|}{ Laboratory Test } & $\begin{array}{l}\text { Laboratory test } \\
\text { at admission }\end{array}$ & $\begin{array}{l}\text { Laboratory test at second } \\
\text { day }\end{array}$ \\
\hline \multicolumn{2}{|c|}{ Lactate $(0.5-1.8 \mathrm{mmol} / \mathrm{L})$} & 9.5 & 1.7 \\
\hline \multicolumn{2}{|c|}{ Plasma Glucose (70-99mg/dl) } & 230 & \\
\hline \multirow{6}{*}{ Electrolytes } & Sodium (135-145mEq/L) & 142 & 139 \\
\hline & Potassium (3.5-5.5mEq/L) & 3 & 4 \\
\hline & Ionized Calcium (1.13-1.32mmol/L) & 1.15 & 1.4 \\
\hline & Chloride (96-106 mEq/L) & 105 & 105 \\
\hline & Magnesium (1.5-2 mEq/L) & 1.98 & 2 \\
\hline & Phosphorus (3-4.5 mg/dl) & 3.35 & \\
\hline \multirow{5}{*}{ Blood Count } & Haemoglobin (13.5-17.5 gr/dl) & 12.2 & 12 \\
\hline & Haematocrit (40.7-50.3\%) & 36.4 & 36.3 \\
\hline & White Blood Cell (4500-11000 cells) & 17 & 13 \\
\hline & Neutrophils (40-60\%) & $77 \%$ & $70 \%$ \\
\hline & Platelet count (150.000-450.000 cells) & 318 & 310 \\
\hline \multirow{2}{*}{$\begin{array}{l}\text { Arterial Blood } \\
\text { Gases }\end{array}$} & $\mathrm{pH}(7.35-7.45)$ & 7.19 & 7.37 \\
\hline & pCO2 (38-42mmHg) & 39.3 & 34.5 \\
\hline
\end{tabular}




\begin{tabular}{|l|l|l|l|}
\hline & pO2 $(75-100 \mathrm{mmHg})$ & 234.9 & 99.3 \\
\cline { 2 - 4 } & HCO3 $(22-28 \mathrm{mEq} / \mathrm{L})$ & 14.8 & 19.9 \\
\cline { 2 - 4 } & BE $(-5-+5 \mathrm{mEq} / \mathrm{L})$ & -12.6 & -4.6 \\
\cline { 2 - 4 } & Fraccion of inspired oxygen & $35 \%$ & $21 \%$ \\
\hline
\end{tabular}

Table 2: Hyperlactataemia types and the main causes

\begin{tabular}{|c|c|c|}
\hline Type A & Typ & \\
\hline O Shock (hypovolemic, cardiogenic, septic) & & ○ Severe liver disease \\
\hline$\circ$ Arterial embolism & P1 & ○ Thiamine deficiency \\
\hline ○ Severe anaemia & $\mathrm{D} \perp$ & $\circ$ Renal failure \\
\hline o Severe hypoxemia & & ○ Malignancy \\
\hline $\begin{array}{l}\text { Excessive increase in oxygen demand } \\
\text { (seizure, hyperpyrexia, shivering, strenuous exercise) }\end{array}$ & B2 & $\begin{array}{l}\text { Drugs (biguanides, iron, isoniazid, zidovudine, and } \\
\text { salicylates) }\end{array}$ \\
\hline ○ Carbon monoxide toxicity & & $\circ$ Toxins \\
\hline$\circ$ Respiratory failure & B3 & $\begin{array}{ll}\text { O } & \text { Mitochondrial disorders } \\
\circ & \text { Hypoglycaemia } \\
\circ & \text { Inborn errors of metabolism }\end{array}$ \\
\hline
\end{tabular}

